\section{Vitamin E Status and Total Body Water in Children and Adolescents with Sickle Cell Anemia}

\section{Ruth Williams-Hooker ${ }^{1^{*}}$, Karen Ringwald-Smith ${ }^{2}$ and Michelle B Stockton ${ }^{1}$}

${ }^{1}$ Clinical Nutrition Services; School of Health Studies Memphis, University of Memphis, Memphis, USA

${ }^{2}$ Clinical Nutrition Services, Jude Children's Research Hospital, Memphis, USA corrected plasma vitamin E, and TBW below normal, however none of these factors was associated with pain medications. Further research needs to be conducted with a greater sample size and more pain variables.

\section{Introduction and Background}

Sickle Cell Disease (SCD) is a genetic disorder caused by a Hemoglobin Gene Mutation (HbS), which produces abnormal sickle hemoglobin $[1,2]$. The HbS protein molecules adhere to the Red Blood Cells (RBC), and deform them into rigid, sickle or holly-leaf-shaped cells rather than the typical round and flexible shape. Passage through the vessels is more difficult for these deformed RBC's so less oxygen is transported to tissues, leading to vaso-occlusive pain crises, organ damage, stroke, decreased quality of life and early death. In addition, sickled cells have a lifespan of 10-12 days, as opposed to normal RBCs (120 days), which results in chronic anemia. The majority of those afflicted with SCD are of African descent. The most debilitating form of SCD is Sickle Cell Anemia (SCA) ( $\mathrm{Hb}$ SS or $\mathrm{SB}^{0}$-thalassemia) [2]. There are approximately $100,000 \mathrm{SCD}$ patients in the United States [2].

Nutritional concerns for children with SCD include weight loss and poor growth, delayed puberty, vitamin and mineral deficiencies and fluid imbalance [3]. Studies have shown that dietary intake of riboflavin, zinc, calcium, magnesium, phosphorus, protein, and calories fall below recommendations in SCD patients $[4,5]$. Others have found that plasma levels of certain key vitamins, including vitamin E, are lower than reference values [6]. Vitamin E, particularly $\alpha$-tocopherol, is a well-known fat-soluble antioxidant vitamin, found in cell membranes, that provides protection from free radicals. More specifically, vitamin $\mathrm{E}$ has been thought to improve $\mathrm{RBC}$ cell membrane fluidity and safeguard RBCs against oxidative damage which might otherwise shorten RBC lifespan. [7]. In addition, vitamin E plays a role in anti-inflammatory processes, inhibits platelet aggregation, enhances vasodilation and boosts immunity [7].

Natta et al., found that adequate vitamin E status is associated with fewer sickled RBCs [8]. A reduction of irreversibly sickled cells resulted when hemoglobin S-containing erythrocytes were exposed to vitamin $\mathrm{E}$ in vitro [6]. According to Costagliola et al., differences in plasma vitamin E may account for roughly $15 \%$ of improvements in the clinical manifestations among study participants. Excretion, utilization, malabsorption, or a combination of these could be contributing factors to vitamin E deficiency [7].

Proper hydration is an important factor in maintaining homeostasis; it is required for the regulation of body temperature, maintenance of energy levels, adequate digestion and elimination of toxins [9]. In an adequately hydrated person, overall total body water accounts for $55-65 \%$ of overall body weight. Poor hydration elevates the viscosity of the blood, and even mild dehydration impacts hemo-concentration. Dehydration can develop under several conditions, including, but not limited to, diarrhea, severe vomiting, excessive perspiration, or inadequate fluid intake [9]. 
The dietary intake of both sodium and fluids impacts hydration status. Elevated sodium intake results in the movement of water across cell membranes, causing cellular dehydration [9]. Thus, to help prevent intracellular fluid deficits, a moderate intake $(1,500$ milligrams per day) of dietary sodium in SCD patients may prove beneficial in preventing dehydration. Beyer and Simmons increased fluid intake as a comfort measure for sickle cell patients (children and adolescents) and noted a reduction in vaso-occlusion pain [10]. In a pilot study, Williams et al., found children who had SCD (ages 5-17), had reduced fluid intake and elevated sodium intake [11]. Although the patient sample size was not sufficient to correlate fluid status to intakes of fluids and sodium, the study demonstrated trends in fluid status and dietary intakes of sodium and fluids.

The purpose of the current study was to explore vitamin E plasma status, vitamin $\mathrm{E}$ and fluid intake, and total body water status to determine if any of these factors correlate with patient-reported pain medication usage.

\section{Study Design/Methods}

This was a pilot study of children between the ages of 5 and 18 who have SCA and were treated at St. Jude Children's Research Hospital (SJCRH). Eligible children were recruited from SJCRH clinics by their physician or designee, who reviewed the study with the child and caregiver to determine if they would like to participate. If so, the child's caregiver contacted the Principle Investigator to set up an appointment. All research was conducted at the University of Memphis Human Performance Lab (UMHPL). The study was approved by the University of Memphis Institutional Review Board (IRB) and was exempted from IRB review at SJCRH. All participants/caregivers signed assent/consent.

Participants were trained on how to record their fluid and food intake for the three days prior to their UMHPL appointment. Participants were instructed to fast for the 12 hours leading up to their appointment at the UMHPL. Before 9 AM on the scheduled day, participant's fasting specimens were drawn by a phlebotomist. Two tubes of blood were drawn, one for vitamin $\mathrm{E}$ analysis and one for cholesterol. Next, total body water was measured by Bioelectrical Impedance (BIA) (RJL Systems, Quantum III, MI). BIA considers height, weight, age, and gender. After the draw and BIA were competed, each participant was given a snack and drink. Participants were asked to review their drink and food records for details (such as serving size, added salt, etc.) with a member of the study team and to recall their pain medication for the previous month. Food and drink records were entered into the Nutrition Data System for Research-Nutritional Analysis Software, University of Minnesota, 2013 (NDRS) which analyzed food items by a member of the study team, who determined dietary intake of vitamin $\mathrm{E}$ and fluid. Participants recorded their pain medication usage for the past month. Pain medication usage was scored as follows: $1=$ No medications or only over-the-counter over the counter medications; $2=$ Percocetor hydrocodone; $3=$ Three or more medications or stronger medications, such as morphine. Participant's vitamin E status was compared to normal plasma (corrected for cholesterol) for age [12]. Total Body Water (TBW) was compared to normal for age and gender [13]. Dietary intake of vitamin E and fluid were compared to the Recommended Daily Allowance (RDA) and reference standards for age and gender [14]. Vitamin E plasma and TBW were analyzed with respect to vitamin $\mathrm{E}$ and fluid intake, and to pain medication usage.

\section{Statistical Analyses}

The data were analyzed using IBM SPSS version 24.0 for windows with the significance level set at $\mathrm{p}<0.05$. Descriptive analyses included means, standard deviations, frequencies, and percentages of the variables for participants SCA. First, a paired-samples t-test was conducted to compare plasma vitamin $\mathrm{E}$ in recruited participants to reference plasma vitamin E levels based on age [12]. Next, a single sample t-test was used to compare corrected plasma vitamin $\mathrm{E}$ in recruited participants to a $50^{\text {th }}$ percentile referenced vitamin $\mathrm{E}$ ratio $(5.54 \mathrm{mmol} / \mathrm{mol})$ according to a study conducted by Winklhofer-Roob and colleagues [12]. Additional single sample t-tests were used to assess differences among participant's vitamin $\mathrm{E}$ intake to the recommended daily allowances for vitamin $\mathrm{E}$ by age (4-8-year old's; 9-13-year old's; and 14 years and older). Single-sample t-tests were conducted to assess the differences among TBW percentage and the normal TBW percentages based on age. Lastly, overall relationships among vitamin E, TBW, and level of pain were evaluated using Kendall's Tau-b correlations.

\section{Results}

Thirty African American children participated in the study. Half of the participants were female ( $\mathrm{n}=15), 26$ were $\mathrm{HbSS}$ ( 15 female) and 4 were $\mathrm{HB}$ thal $^{0}$ (all male). Ages ranged from 5-17, with the mean being 12.03 years of age. On average, participants reported $5.95 \mathrm{mg}$ of vitamin E intake over a 3-day average and had an average of $6.72 \mathrm{mg} / \mathrm{dl}$ of vitamin E via plasma. The mean TBW of the participants was 27.2 liters $(52 \%)$. Descriptive results are in Table 1.

\begin{tabular}{|c|c|c|}
\hline Variable & Mean (SD) & Min - Max \\
\hline Age-years & $12.03(3.61)$ & $5-7$ \\
\hline Plasma vitamin E-mg/dl & $6.72(2.02)$ & $3.60-11.10$ \\
\hline Reference plasma vitamin E-mg/dl & $5.89(0.13)$ & $5.77-6.21$ \\
\hline Corrected plasma vitamin E-mg/dl & $1.20(0.44)$ & $0.60-2.40$ \\
\hline Vitamin E intake-mg & $5.95(2.37)$ & $2.33-13.98$ \\
\hline Total body water-L & $27.22(7.95)$ & $16.50-40.00$ \\
\hline Percent total body water & $52.08(10.54)$ & $32.20-69.80$ \\
\hline Pain level-scale 1-3 & $1.25(1.14)$ & $0-3$ \\
\hline
\end{tabular}

Table 1: Descriptive results of participants $(\mathrm{N}=30)$.

\section{Vitamin E Comparisons}

A paired-samples t-test indicated that there was a significant difference in the participants' plasma vitamin E (alpha-tocopherol) (M $=6.72, \mathrm{SD}=2.02)$ and the reference plasma vitamin $\mathrm{E}$ levels based on age $(\mathrm{M}=5.89, \mathrm{SD}=0.13) ; \mathrm{t}(29)=2.30, \mathrm{p}<0.05$. Specifically, the results indicated that the participant's plasma vitamin E was significantly higher than the reference plasma vitamin E levels. However, single sample t-tests were also conducted to compare corrected plasma vitamin $\mathrm{E}$ in recruited participants to the reference for plasma alpha-tocopherol: Cholesterol ratio at the $50^{\text {th }}$ percentile according to the study by Winklhofer-Roob, Van't Hof, \& Shmerling where the value for alpha-tocopherol: Cholesterol ratio $=5.45 \mathrm{mmol} / \mathrm{mol}$ [14]. There was a significant difference in the participant's corrected plasma vitamin $\mathrm{E}(\mathrm{M}=1.2, \mathrm{SD}=0.44)$ and the reference for plasma alpha-tocopherol: Cholesterol ratio at the $50^{\text {th }}$ percentile; $t(29)=$ 
$-53.36, \mathrm{p}<0.0001$. These results indicated that the corrected vitamin E levels were significantly lower than the $50^{\text {th }}$ percentile reference for plasma alpha-tocopherol: cholesterol ratio.

Single sample t-tests were conducted to compare self-reported vitamin $\mathrm{E}$ intake to RDAs of vitamin $\mathrm{E}$ in participants by age. For participants who were between 4 and 8 years of age $(n=5)$, there was no significant difference in the participant's average 3-day vitamin $\mathrm{E}$ intake $(\mathrm{M}=5.14, \mathrm{SD}=2.42)$ and the $\mathrm{RDA}$ recommendation for vitamin $\mathrm{E}(7 \mathrm{mg}) ; \mathrm{t}(4)=-1.72, \mathrm{p}=0.16)$. For participants who were between 9 and 13 years old $(n=14)$, there was a statistically significant difference in the participants' average 3-day vitamin $\mathrm{E}$ intake $(\mathrm{M}=5.51$, $\mathrm{SD}=1.54)$ and the RDA recommendation for vitamin $\mathrm{E}(11 \mathrm{mg}) ; \mathrm{t}$ $(13)=-13.39, p<0.0001$. These results indicated that the vitamin $\mathrm{E}$ intake was significantly lower than the RDA recommendations. For participants aged 14 and older $(n=10)$, there was a statistically significant difference in the participant's average 3-day vitamin $\mathrm{E}$ intake $(\mathrm{M}=6.99, \mathrm{SD}=3.11)$ and the RDA recommendation for vitamin $\mathrm{E}$ $(15 \mathrm{mg}) ; \mathrm{t}(9)=-8.14, \mathrm{p}<0.0001$. These results indicate that vitamin E intake was significantly lower than the RDA recommendations.

\section{Total Body Water Comparisons}

Single sample t-tests were conducted to evaluate whether there were differences among participant's TBW percentage and the normal TBW percentages based on age. For participants who were 10 years old and younger $(n=8)$, there was no significant difference in the participant's average TBW percentage $(\mathrm{M}=55.4 \%, \mathrm{SD}=9.68)$ compared to reference values (TBW percentage for this age group $(61.5 \%) ; \mathrm{t}(7)=-1.79, \mathrm{p}=0.12)$. For participants who were 11 years old and older $(\mathrm{n}=16)$, there was significant difference in the participant's TBW percentage $(\mathrm{M}=50.4 \%, \mathrm{SD}=10.87)$ and the reference TBW percentage for this age group $(57.3 \%) ; \mathrm{t}(15)=-2.52, \mathrm{p}=0.02)$.

\section{Relationships among Variables}

Kendall's tau-b correlations were conducted to compare relationships among vitamin $\mathrm{E}$ variables, intake, plasma levels, total body water percent, and level of pain (scored 1,2, or 3). No significant relationships were discovered (Table 2).

\begin{tabular}{|c|c|c|}
\hline & $\begin{array}{c}\text { TBW } \\
\mathbf{r}_{\tau}(\mathbf{p} \text {-value) }\end{array}$ & $\begin{array}{c}\text { Pain Level } \\
\mathbf{r}_{\tau}(\mathbf{p} \text {-value) }\end{array}$ \\
\hline Corrected plasma vitamin E mg/dl & $0.087(0.617)$ & $-0.169(0.269)$ \\
\hline Plasma vitamin E mg/dl & $-0.165(0.326)$ & $-0.073(0.620)$ \\
\hline Vitamin intake mg & $0.190(0.272)$ & $0.092(0.541)$ \\
\hline
\end{tabular}

Table 2: Correlations $\left(r_{\tau}\right)$ among vitamin E, plasma levels, intake, and total body water and pain level.

\section{Discussion}

Study participants exhibited normal plasma vitamin E levels. However, when corrected for cholesterol, their levels were significantly lower than reference levels [12]. Hamdy et al., evaluated plasma selenium and vitamin E levels in transfusion-dependent Egyptian children with SCD or Thalassemia (TM) to determine if these levels correlated to iron overload status or transfusion requirements [15]. Ninety children participated in the study, 30 with SCD, 30 with TM and 30 healthy controls. Results revealed depleted selenium and vitamin $\mathrm{E}$ levels in children with $\mathrm{TM}$ and $\mathrm{SCD}$ relative to healthy controls, which supports the findings of the current study where participants had significantly lower corrected plasma vitamin E levels than reference levels. Mandese et al., also found children with SCD to have many vitamin deficiencies, including vitamin $\mathrm{E}$ [16].

The younger participants consumed more vitamin $\mathrm{E}$ than the two older age groups, with greater significance among oldest participants. Like Kawchak et al. [4], the current study found the adequacy of nutrition intake decreases with age in children and adolescents with SCD.

By the same token, the older children's TBW were significantly lower than reference TBW, while younger children's TBW were not. Low TBW could reflect poor fluid intake based on food records. Low consumption of vitamin $\mathrm{E}$ and fluid intake indicate that the older children may have poorer overall nutrient intake than the younger children. It would stand to reason then, that the older children who have lower TBW would have reported higher usage of pain medication, however this was not the case in our study. We found no relationship between TBW, sodium intake and pain medication usage. With any child, as they get older and have more control of the foods they eat, they are more likely to eat more "junk" foods and soda [17]. Two possible factors that may explain the lower TBW levels in the older children are sodium intake and soda consumption as both are known diuretics. Yang et al., looked at the sodium intake of adolescents and found they consumed an average of $3387 \mathrm{mg} /$ day of sodium per day [18]. Williams et al., also found high sodium intake in their patients with SCD [11]. An interesting study conducted by, Videon and Manning looked at overall fruit and vegetable intake in adolescents. The study included 18,177 adolescents who were part of the National Longitudinal Study of Adolescent Health, whose goal was to provide national estimates of the frequency and determinants of adolescents' consumption of fruits and vegetables [18]. Almost one in five adolescents reported skipping breakfast the previous day. Additionally, a large percentage of adolescents reported eating less than the recommended amount of vegetables (71\%), fruit (55\%), and dairy foods $(47 \%)$. One would assume that these low finding of fruit and vegetable intake would be found in children and adolescents diagnosed with SCD and that this could contribute to the low vitamin E intakes observed in our study.

Natta et al., found that vitamin $\mathrm{E}$ is essential for clearing sickle cells from the blood and reducing pain [8]. However, based on low corrected plasma vitamin E levels, our study participants did not experience a significant increase in pain medication use (on a threepoint scale).

Lastly, TBW and Vitamin E intake and status was compared to pain scores. There was no sign of a relationship between any of the variables. When looked at by age groups, there was no correlation of TBW Vitamin E status and intake, and pain scores, indicating that although children had poorer nutrition intake as they get older, it was not related to pain medications.

This study provides insight into vitamin E status and intake and TBW in child and adolescent pain scores. Pain in children and adolescents with SCD was not related to vitamin E intake or status, or TBW. Future studies with a larger sample size and more pain variables is warranted. 


\section{Acknowledgement}

This study was funded by the Pediatric Nutrition Practice Group (PNPG) of the Academy of Nutrition and Dietetics (AND).

\section{References}

1. Steinberg MH (2008) Sickle cell anemia, the first molecular disease: Overview of molecular etiology, pathophysiology, and therapeutic approaches. ScientificWorldJournal 8: 1295-1324.

2. National Heart, Lung, and Institute (2016) What is sickle cell anemia? $\mathrm{NIH}$, Bethesda, Maryland, USA.

3. Hyacinth HI, Gee BE and Hibbert JM (2010) The role of nutrition in sickle cell disease. Nutr Metab Insights 3: 57-67.

4. Kawchak DA, Schall JI, Zemel BS, Ohene-Frempong K, Stallings VA (2007) Adequacy of dietary intake declines with age in children with sickle cell disease. J Am Diet Assoc 107: 843-848.

5. Williams R, George EO, Wang W (1997) Nutrition assessment in children with sickle cell disease. J Assoc Acad Minor Phys 8: 44-48.

6. Phillips G, Tangney CC (1992) Relationship of plasma alpha tocopherol to index of clinical severity in individuals with sickle cell anemia. Am J Hematol 41: 227-231.

7. Costagliola C, Iuliano G, Menzione M, Rinaldi E, Vito P, et al. (1996) Effect of vitamin $\mathrm{E}$ on glutathione content in red cells, aqueous humor and lens of humans and other species. Exp Eye Res 43: 905-914.

8. Natta CL, Machlin LJ, Brin M (1980) A decrease in irreversibly sickled erythrocytes in sickle cell anemia patients given vitamin E. Am J Clin Nutr 33: $968-971$.
9. Berne R, Levy M (1998) Physiology, (2nd edn). CV Mosby, St Louis, USA.

10. Beyer JE, Simmons LE (2004) Home treatment of pain for children and adolescents with sickle cell disease. Pain Manag Nurs 5: 126-135.

11. Williams-Hooker R, Ringwald Smith K, Hankins J, Shurley TA, Stockton MB (2013) Evaluation of hydration status, sodium and fluid intake in children with sickle cell anemia. J Blood Disord Transfus 4: 143.

12. Winklhofer-Roob BM, van't Hof MA, Shmerling DH (1997) Reference values for plasma concentrations of vitamin $\mathrm{E}$ and $\mathrm{A}$ and carotenoids in a swiss population from infancy to adulthood, adjusted for seasonal influences. Clin Chem 43: 146-153.

13. Alpers DH, Bier DM, Taylor BE (2016) Manual of nutritional therapeutics, (6th edn). Lippincott Williams \& Wilkins, Philadelphia, USA.

14. Dietary Reference Index (2017) Recommended Dietary Allowance.

15. Hamdy MM, Mosallam DS, Jamal AM, Rabie WA (2015) Selenium and vitamin $\mathrm{E}$ as antioxidants in chronic hemolytic anemia: Are they deficient? A case-control study in a group of Egyptian children. J Adv Res 6: 10711077.

16. Mandese V, Marotti F, Bedetti L, Bigi E, Palazzi G, et al. (2016) Effects of nutritional intake on disease severity in children with sickle cell disease. Nutr J 15: 46.

17. Videon TM, Manning CK (2003) Influences on adolescent eating patterns: The importance of family meals. J Adolesc Health 32: 365-373.

18. Yang Q, Zhang Z, Kuklina EV, Fang J, Ayala C, et al. (2012) Sodium intake and blood pressure among US children and adolescents. Pediatrics 130: 611-619. 